\title{
Assessment of committed doses received by agricultural workers in grain harvesting operations in the areas of radioactive contamination
}

\author{
A. Podolyak ${ }^{1, *}$, S. Tagai ${ }^{1}$, E. Nilova ${ }^{1}$ and V. Averin ${ }^{2}$ \\ ${ }^{1}$ Research Institute of Radiology, 16, Ul. Fedyuninskogo, 246000 Gomel, Belarus. \\ 2 Biology Department, Gomel State University, n.a. F. Skaryna, 102, Ul. Sovietskaya, 246000 Gomel, Belarus.
}

Received: 7 June 2016 / Accepted: 11 January 2017

\begin{abstract}
Implementation of field experiments took place in two farmland fields located in Bragin district of Gomel region, Belarus, i.e. a plot of land in the resettled area and a backyard crop field in a populated area of the district. The objective of research was to study the levels of radioactive contamination of air in the workplace of agricultural workers during intensive grain harvesting operations. Comparative dose analysis was done to assess external exposure and committed effective doses of internal exposure received by agricultural workers due to inhalation of grain dust containing ${ }^{241} \mathrm{Am},{ }^{238,239+240} \mathrm{Pu},{ }^{137} \mathrm{Cs}$ and ${ }^{90} \mathrm{Sr}$. According to the results, the dominant contributors (82-97\%) to internal exposure of agricultural workers both on a private farm field and in the resettled area, were the transuranium elements ${ }^{241}$ Am and ${ }_{238,239+240} \mathrm{Pu}$. In the context of total doses received by harvest workers, the most significant contribution was caused by external exposure which was 2-3 orders of magnitude higher than the levels of internal exposure due to inhalation intake of radionuclides.
\end{abstract}

Keywords: transuranium element $/{ }^{137} \mathrm{Cs} /{ }^{90} \mathrm{Sr} /$ inhalation / effective dose

\section{Introduction}

Taking into account the half-lives of the main radionuclides of the Chernobyl origin, i.e. ${ }^{137} \mathrm{Cs}\left(\mathrm{T}_{1 / 2}=30\right.$ years $)$ and ${ }^{90} \mathrm{Sr}\left(\mathrm{T}_{1 / 2}=28.5\right.$ years $)$, the challenging issues start to emerge concerning resuming the use of former agricultural lands characterized by the finest natural soil fertility though excluded from farm production in the aftermath of the Chernobyl accident. In addressing such issues special concerns relate to the alpha-emitting transuranium elements (TUE) ${ }^{241} \mathrm{Am}$ and ${ }^{238,239+240} \mathrm{Pu}$ which may be present in these lands alongside with the other dispersed radioactive contaminants. Thus, additional efforts have to be provided in order to estimate yet more precisely the committed effective doses received by agricultural workers via inhalation intake of radioactive airborne dust in the process of intensive grain harvesting operations. Affecting soil surface, such operations result in radionuclides, otherwise fixed in soil, to rise up in the air together with dust particulates and therefore contribute in developing internal exposure of harvest workers through inhalation pathway.

This research paper presents the results of comparative analysis of external exposure and committed effective doses

\footnotetext{
* Corresponding author: office@rir.by
}

of internal exposure received by agricultural workers due to inhalation intake of ${ }^{241} \mathrm{Am},{ }^{238,239+240} \mathrm{Pu},{ }^{137} \mathrm{Cs}$ and ${ }^{90} \mathrm{Sr}$ in the process of harvesting grain crops from the backyard located in a populated area and from the experimental plot of land located in the resettled area of the Chernobyl evacuation zone in Gomel region, Belarus. Two categories of agricultural workers involved in grain harvesting operations were subject to the analysis: (1) operators of combine harvesters and (2) agrarians or members of the general public employed in agricultural works directly on the field.

\section{Materials and methods}

The first experimental field, with a total area of 3.6 ha, was the one located close to the former inhabited area named Rafalov (Bragin district, Gomel region, Belarus) $42 \mathrm{~km}$ from the Chernobyl NPP within the boundaries of the State Polessye Radiation-Ecological Reserve (PRER) (Fig. 1), characterized by sod-podzolic sandy loam soils and high levels of radioactive contamination densities: ${ }^{137} \mathrm{Cs} 993 \mathrm{kBg} \mathrm{m}^{-2}$ $\left(26.8 \mathrm{Ci} \mathrm{km}^{-2}\right),{ }^{90} \mathrm{Sr} \quad 91.2 \mathrm{kBq} \mathrm{m}^{-2} \quad\left(2.5 \mathrm{Ci} \mathrm{km}^{-2}\right),{ }^{241} \mathrm{Am}$ $5.0 \mathrm{kBq} \mathrm{m}^{-2}\left(0.14 \mathrm{Ci} \mathrm{km}^{-2}\right),{ }^{238} \mathrm{Pu} 1.0 \mathrm{kBq} \mathrm{m}^{-2}\left(0.03 \mathrm{Ci} \mathrm{km}^{-2}\right)$, ${ }^{239+240} \mathrm{Pu} 2.6 \mathrm{kBq} \mathrm{m}^{-2}\left(0.07 \mathrm{Ci} \mathrm{km}^{-2}\right)$. Since this field is located in the resettlement zone, implementation of economic activities in this area is subject to special national regulations. 


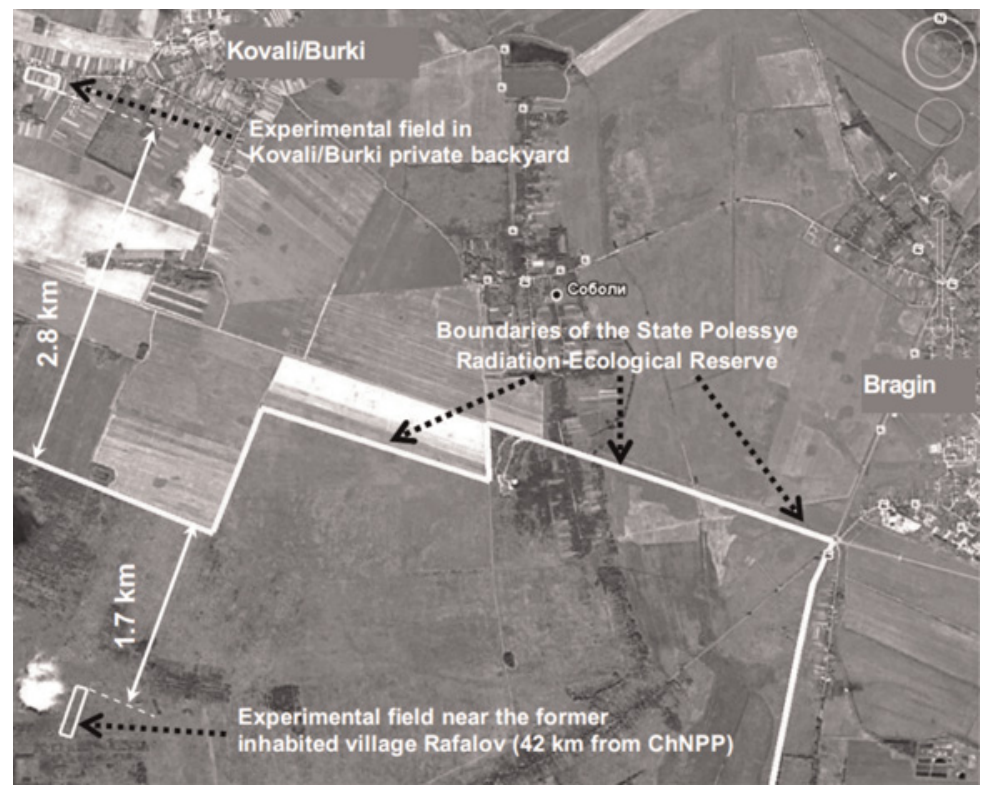

Fig. 1. Location of both experimental fields with respect to the PRER borders (as shown on the satellite image).

According to the legislation of the Republic of Belarus, the presence and implementation of any economic activities by the members of general public in the resettlement zone is prohibited. Only personnel members or individuals designated as personnel are eligible to implement any such activities in the resettlement zone.

The second experimental field was selected to be in the PRER neighborhood, attached to Kovali and Burki villages of the same district, and located about $50 \mathrm{~km}$ from the Chernobyl NPP (Fig. 1). This private backyard, with a total area of $2.8 \mathrm{ha}$, is continuously used by the local residents for growing grain crops. Characterized by the same type of soil as that of the first experimental field, its radioactive contamination densities were as follows: ${ }^{137} \mathrm{Cs} 243 \mathrm{kBq} \mathrm{m}^{-2}\left(6.6 \mathrm{Ci} \mathrm{km}^{-2}\right),{ }^{90} \mathrm{Sr}$ $29 \mathrm{kBq} \mathrm{m}^{-2}\left(0.8 \mathrm{Ci} \mathrm{km}^{-2}\right),{ }^{241} \mathrm{Am} 2.0 \mathrm{kBq} \mathrm{m}^{-2}\left(0.06 \mathrm{Ci} \mathrm{km}^{-2}\right)$, ${ }^{238} \mathrm{Pu} \quad 0.4 \mathrm{kBq} \mathrm{m}^{-2}\left(0.01 \mathrm{Ci} \mathrm{km}^{-2}\right),{ }^{239+240} \mathrm{Pu} 1.0 \mathrm{kBq} \mathrm{m}^{-2}$ (0.03 $\left.\mathrm{Ci} \mathrm{km}^{-2}\right)$.

Grain crops (i.e. wheat, triticale, and barley) from Kovali/ Burki experimental field and winter rape from Rafalov field were harvested with a "Polessye $10 \mathrm{~K}$ " combine harvester with an operator's cabin equipped with an air conditioning system. It should be mentioned however, that, while harvesting in Kovali/Burki, the operator of a "Polessye 10K" combine harvester often preferred to leave the door open, rather than use air conditioning in a sealed cabin. For gathering winter triticale from the field of Rafalov a "Lida 1300" combine harvester was used, with no air conditioning system inside the cabin.

The experiment took place within a harvesting period starting from the late July till the early August. During this whole period, the weather in both experimental fields was dry and sunny, with no precipitation. The air temperature was in the range of $28-30{ }^{\circ} \mathrm{C}$, and relative humidity did not exceed $30 \%$.

Assessment of activity concentrations of ${ }^{137} \mathrm{Cs},{ }^{90} \mathrm{Sr}$ and TUE isotopes $\left({ }^{241} \mathrm{Am}\right.$ and $\left.{ }^{238,239+240} \mathrm{Pu}\right)$ in the air was done based on air sampling. Samples were collected both in the air of grain harvesting area (workplace), i.e. "on the field", and inside the operator's cabin of a combine harvester, i.e. "in the cab", by means of air pumping through sampling filters of portable aspirator pumps. Air sampling "in the cab" was done with the use of a Portable Sampling Unit model 04A. Sampling "on the field" was done by four H-810 model Filter/ Fan Units placed along the windward side of the field and used simultaneously. For filtering materials, Petryanov's filtering cloth was used, an ultra-thin synthetic fabrics with an average fiber diameter of 1.5 microns. In order to obtain a detectable (i.e. $>$ MDA, Minimum Detectable Activity) value of radionuclide activity, the filters labeling "on the field" workplace were combined into a single sample. Mass concentrations of dust were measured in a gravimetric procedure by having each of the four filters weighed before and after sampling.

The external dose rates of gamma-radiation were determined with the use of a MKS-AT 1125 dosimeter/radiometer. Concentrations of ${ }^{137} \mathrm{Cs},{ }^{241} \mathrm{Am}$ in soil samples, and ${ }^{137} \mathrm{Cs}$ air concentrations in air samples were measured by a Canberra Gamma Analyst ${ }^{\mathrm{TM}}$ spectrometer of extended energy range, equipped with a GX3020 detector with a beryllium window. The method of radiochemical purification (IAEA, 1999) was used to determine activity concentrations of ${ }^{90} \mathrm{Sr}$ and TUE in air samples. The same procedure was used to measure specific activities of ${ }^{238} \mathrm{Pu},{ }^{239+240} \mathrm{Pu}$ and ${ }^{90} \mathrm{Sr}$ in soil samples. The radiochemical procedure included (a) ashing of air filters, (b) acid digestion, (c) concentration and purification from alkali and alkaline earth metals, (d) $\mathrm{Pu}$ stabilization in its quadrivalent state, (e) Am purification from $\mathrm{Pu}$ (IV) with anion exchange resin, (f) Am purification from $\mathrm{Sr}$ (II) and $\mathrm{Fe}$ (II) with TRU-Spec extraction chromatography resin, (g) Am purification from rare earth elements (lanthanides) with TEVA-Spec extraction chromatography resin, and (h) electrodeposition of $\mathrm{Pu}$ and $\mathrm{Am}$ on a polished, stainless steel plate with an active spot of $25 \mathrm{~mm}$ in diameter.

Detection of TUE was performed using a Canberra Alpha Analyst ${ }^{\mathrm{TM}}$ spectrometer equipped with a silicon semiconductor PIPS detector, with energy resolution of $<15 \mathrm{keV}$, detector efficiency of no less than $18 \%$ (for detector-source spacing of 
Table 1. The concentrations of ${ }^{137} \mathrm{Cs},{ }^{90} \mathrm{Sr}$ and TUE $\left({ }^{241} \mathrm{Am},{ }^{238,239+240} \mathrm{Pu}\right)$ in the workplace air during grain harvesting operations.

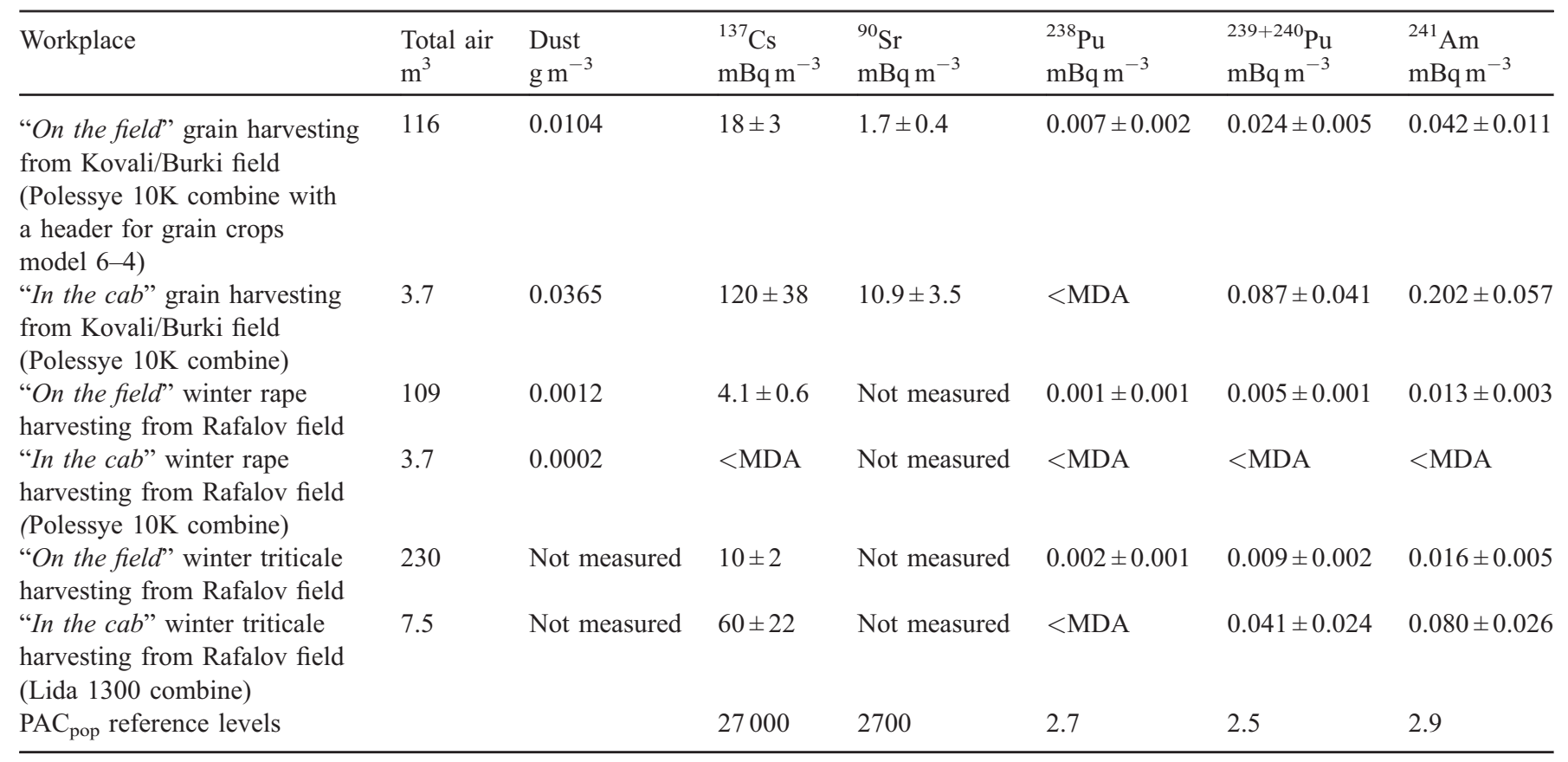

less than $5 \mathrm{~mm}$ ), background $<1 \mathrm{counth}^{-1}$, counting time per sample 1-4 days. The count rate of beta particles from ${ }^{90} \mathrm{Sr}$ source was measured using an in situ Canberra model 5SE low background gas proportional counter. The chemical yield varied in the range of $80-95 \%$. The minimum detectable activities (MDA) in air samples varied depending on sample volumes amounting to $0.001 \mathrm{~Bq}$ per sample for ${ }^{241} \mathrm{Am},{ }^{238,239+240} \mathrm{Pu}$, $0.1 \mathrm{~Bq}$ per sample for ${ }^{90} \mathrm{Sr}$, and $0.9 \mathrm{~Bq}$ per sample for ${ }^{137} \mathrm{Cs}$. Considering that the area of experimental fields was only $2-4$ ha, each dust sampling was done in a matter of several hours, which, in its turn, was the main restricting factor for the volumes of air samples which varied between $3.7 \mathrm{~m}^{3}$ ("in the cab" sampling) and $230 \mathrm{~m}^{3}$ ("on the field" sampling).

Assessment of committed effective doses received by harvest workers due to inhalation intake of radionuclides during dusty harvesting operations was carried out in full correspondence with the national and international radiation safety standards as recommended by the International Atomic Energy Agency (IAEA, 2000; NRB, 2000; IAEA, 2011; CRIA, 2012; RSR, 2012).

\section{Results and discussion}

The results of ${ }^{137} \mathrm{Cs},{ }^{90} \mathrm{Sr}$ and TUE concentrations measured in air samples collected during grain harvesting operations from the two experimental fields are shown in Table 1. The air concentrations of each analyzed radionuclide $\left({ }^{241} \mathrm{Am},{ }^{238} \mathrm{Pu},{ }^{239+240} \mathrm{Pu},{ }^{137} \mathrm{Cs},{ }^{90} \mathrm{Sr}\right)$ were compared against the average annual Permissible Activity Concentration levels for the population $\left(\mathrm{PAC}_{\mathrm{pop}}\right)$ specified in the national NRB2000 Basic Radiation Safety Standards (NRB, 2000). However, the current regulations in force (CRIA, 2012; $\mathrm{RSR}$, 2012) do not establish the unified $\mathrm{PAC}_{\text {pop }}$ values and instead recommend to calculate these values with reference to the basic dose limit established for "personnel" $\left(20 \mathrm{mSv} \mathrm{y}^{-1}\right)$ and "general public" $\left(1 \mathrm{mSv} \mathrm{y}^{-1}\right)$, and set them as independent sanitary standards for different types of work under the authority of the Ministry of Health. According to the major requirement under these regulations, in cases when an individual is simultaneously exposed both to external and internal sources of radiation, the total effective dose must not exceed the basic dose limits.

According to the results, the highest dust concentration $\left(36.5 \mathrm{mg} \mathrm{m}^{-3}\right)$ was found in the operator's cabin of a Polessye $10 \mathrm{~K}$ combine harvester kept in the open state during the whole harvesting period in Kovali/Burki backyard. By contrast to this, during winter rape harvesting from the field in the resettled area near the former village Rafalov, the air in an isolated and wellconditioned cabin of the same combine harvester was found to be characterized by the lowest dust concentration $\left(0.2 \mathrm{mg} \mathrm{m}^{-3}\right)$. This important condition was the reason why the concentration values of all analyzed radionuclides (i.e. ${ }^{241} \mathrm{Am},{ }^{238} \mathrm{Pu}$, ${ }^{239+240} \mathrm{Pu},{ }^{137} \mathrm{Cs}$ ) in the air were less than the MDA.

Thus, when harvesting in the open Polessye $10 \mathrm{~K}$ combine cabin, the dust burden on the operator's respiratory system was more than 100 times higher than the dust burden to which an operator in a closed, conditioned cabin was exposed. Such significant difference in dust exposure therefore resulted in noticeable difference between the values of activity concentrations of the target radionuclides (Tab. 1).

Despite the fact that the levels of contamination densities of ${ }^{137} \mathrm{Cs},{ }^{90} \mathrm{Sr},{ }^{241} \mathrm{Am}$ and ${ }^{238,239+240} \mathrm{Pu}$ radionuclides in soil of the field in the resettled area were up to 3 times higher than those found in the private backyard of the residential area, harvesting grains in the Kovali/Burki field happened to be attended by significantly greater amounts of airborne dust when compared with harvesting winter triticale and winter rape from the field of Rafalov, making it possible to obtain detectable values of activity concentrations of the analyzed 
radionuclides. The same phenomenon was described by Konoplya et al. (2009). According to their observations held in Bragin areas during 1990-2006, the values of TUE concentrations in the air during harvesting operations in spring and autumn, despite their lesser contamination densities in soil, were equal and in some cases above the similar values found in the resettlement area.

Comparing the above results with the NRB-2000 reference levels, the activity concentrations of ${ }^{137} \mathrm{Cs},{ }^{90} \mathrm{Sr},{ }^{241} \mathrm{Am}$ and ${ }^{239+240} \mathrm{Pu}$ in the most dusty workplace ("in the cab" harvesting on Kovali/Burki field) made up respectively $0.4 \%, 0.4 \%, 7.0 \%$ and $3.5 \%$ of the annual average permissible activity concentrations in the inhaled air established for the population $\left(\mathrm{PAC}_{\mathrm{pop}}\right)$. At the same time, based on the results of the first post-accident aerosol sampling of 26 May 1986 carried out in Bragin town (located in $\sim 50 \mathrm{~km}$ area of ChNPP, same as Kovali and Burki villages), the values of ${ }^{239+240} \mathrm{Pu}$ contents in the air were $6.2 \mathrm{pCim}^{-3}$ (Lebedev et al., 1992), or $230 \mathrm{mBq}$ $\mathrm{m}^{-3}$, which was significantly, by two orders of magnitude, higher than the $\mathrm{PAC}_{\text {pop. }}$

In the case of the Lida 1300 combine harvester, the series with no fitted conditioner, the operator's cabin required continuous airing through the open window apertures during the whole working period, causing the upraised radioactive particles to freely enter in. On the other hand, the cabin of the Polessye $10 \mathrm{~K}$ combine harvester is a model equipped with a conditioner. Besides, during winter rape harvesting from the field of Rafalov it was kept closed, therefore providing for the lowest measurement results as far as the activity concentrations in the workplace air are concerned. Yet, the highest levels of activity concentrations of all target radionuclides were found "in the cab" of the Polessye $10 \mathrm{~K}$ combine harvester due to its permanent open state and increased dust release during grain harvesting from the field of Kovali/Burki.

Thus, the maximum levels of radionuclide activity concentrations in the air of operator workplace can be potentially observed in the cabins lacking appropriate sealing conditions. Hence, maintaining sealing integrity of the operator's cabin should be also deemed an essential requirement of radiation protection of machinery operators involved in agricultural operations on the territories of radioactive contamination.

The values of radionuclide concentration in the air of working areas as shown in Table 1 were then used for estimating committed effective doses of internal exposure received by harvest workers per $1 \mathrm{~h}$ via inhalation intake of ${ }^{241} \mathrm{Am},{ }^{238,239+240} \mathrm{Pu},{ }^{137} \mathrm{Cs}$, and ${ }^{90} \mathrm{Sr}$ (Tab. 2).

Internal exposure dose rates in Table 2 were calculated based on the dose coefficients corresponding to all available types of lung absorption (F, M, S), particle sizes of $1 \mu \mathrm{m}$ and $5 \mu \mathrm{m}$ ) for all estimated radionuclides, both for personnel and for general public (IAEA, 2011).

Both international and national standards require different dose coefficients to be used in relation to workers and members of the public. In the present study, doses were calculated using dose coefficients for members of the public with regard to Kovali/Burki site being a residential area, because harvesting operations engaged individuals from among local population. At the same time, with regard to Rafalov site being a resettlement area, dose coefficients for workers were used, because the works there can only engage individuals who are officially assigned as personnel members. However, the local specifics is such that the same agricultural workers can be engaged in farm operations in a resettlement area as 'personnel' and also be the ones who work in the adjacent residential area as mere 'agricultural workers'. Therefore, this study is purposefully dedicated to assessing radiation doses to agricultural workers as a whole, without focusing much on making distinctions between these two categories.

Additionally, the values of internal exposure due to inhalation of radionuclides were calculated taking into account the breathing rates derived from the national regulatory standards (CRIA, 2012) established for personnel $\left(V=2400 \mathrm{~m}^{3}\right.$ year $^{-1}$, $\left.t=1700 \mathrm{~h} \mathrm{year}^{-1}\right)$ and the general public $\left(V=8100 \mathrm{~m}^{3}\right.$ year $^{-1}$, $t=8800$ h year $^{-1}$ ).

According to the results, the highest effective dose rate due to inhalation intake of ${ }^{137} \mathrm{Cs},{ }^{90} \mathrm{Sr}$ and total TUE isotopes $\left({ }^{241} \mathrm{Am}+{ }^{238,239+240} \mathrm{Pu}\right)$ was registered in the cabin of the Polessye $10 \mathrm{~K}$ combine's operator when harvesting grain crops from the private field of Kovali/Burki under conditions of hot and dry weather and increased dust generation.

From the obtained measurement results it can be inferred that during implementation of grain dust operations in either the operator's cabin or directly on the field the prevailing contribution to the total effective doses received by farm workers would be made by external exposures. Even in the increased dust conditions, during "in the cab" harvesting on the field of Kovali/Burki, the committed effective dose of internal exposure due to ${ }^{137} \mathrm{Cs},{ }^{90} \mathrm{Sr}$ and TUE total inhalation exposure made the range of $4.9 \times 10^{-6}$ to $3.3 \times 10^{-5} \mathrm{mSv} \mathrm{h}^{-1}$, that is 5-34 times lower than the measured dose of external exposure "on the field" of Kovali/Burki $\left(1.7 \times 10^{-4} \mathrm{mSv} \mathrm{h}^{-1}\right)$. At the same time, the value of internal dose rate "in the cab" was 40 times lower than the value of external dose rate "in the cab". Retrospectively, the results of internal dose estimates performed in the first days after the Chernobyl accident for the residents of contaminated areas in Gomel region (Kut'kov et al., 1996), also show that inhalation intake of airborne particles of nuclear fuel was not significant and had little impact on the doses of internal and external exposure associated with I, Cs and $\mathrm{Sr}$ isotopes.

Moreover, the committed effective doses of internal exposure of the field harvest workers due to inhalation intake of radionuclides were up to one order of magnitude lower when compared to the respective doses received by an operator in the unconditioned cabin.

Figure 2 graphically shows the structure of the committed effective dose rates due to inhalation intake of ${ }^{241} \mathrm{Am}$, ${ }^{238,239+240} \mathrm{Pu},{ }^{137} \mathrm{Cs}$ and ${ }^{90} \mathrm{Sr}$ by the grain harvest workers on both experimental fields.

According to the results, the radionuclides prevailing in the structure of the committed effective dose rates due to inhalation were ${ }^{241} \mathrm{Am}$ and ${ }^{238,239+240} \mathrm{Pu}$ with the contribution of $82-97 \%$ against only $3-18 \%$ from ${ }^{137} \mathrm{Cs}$ and ${ }^{90} \mathrm{Sr}$.

The average time spent by fieldsmen and machinery operators on grain harvesting operations was 14 days, or $140 \mathrm{~h}$ given that the working activity during the harvest period commonly lasts up to $10 \mathrm{~h}$. Considering this, the total annual effective doses (total effective dose of external exposure and committed dose of internal exposure) to these two categories of agricultural workers involved in grain dust operations on the experimental fields were calculated to constitute respectively $6 \times 10^{-2} \mathrm{mSv}_{\text {year }}{ }^{-1}$ and $2-3 \times 10^{-2} \mathrm{mSv}_{\text {year }}{ }^{-1}$, or 


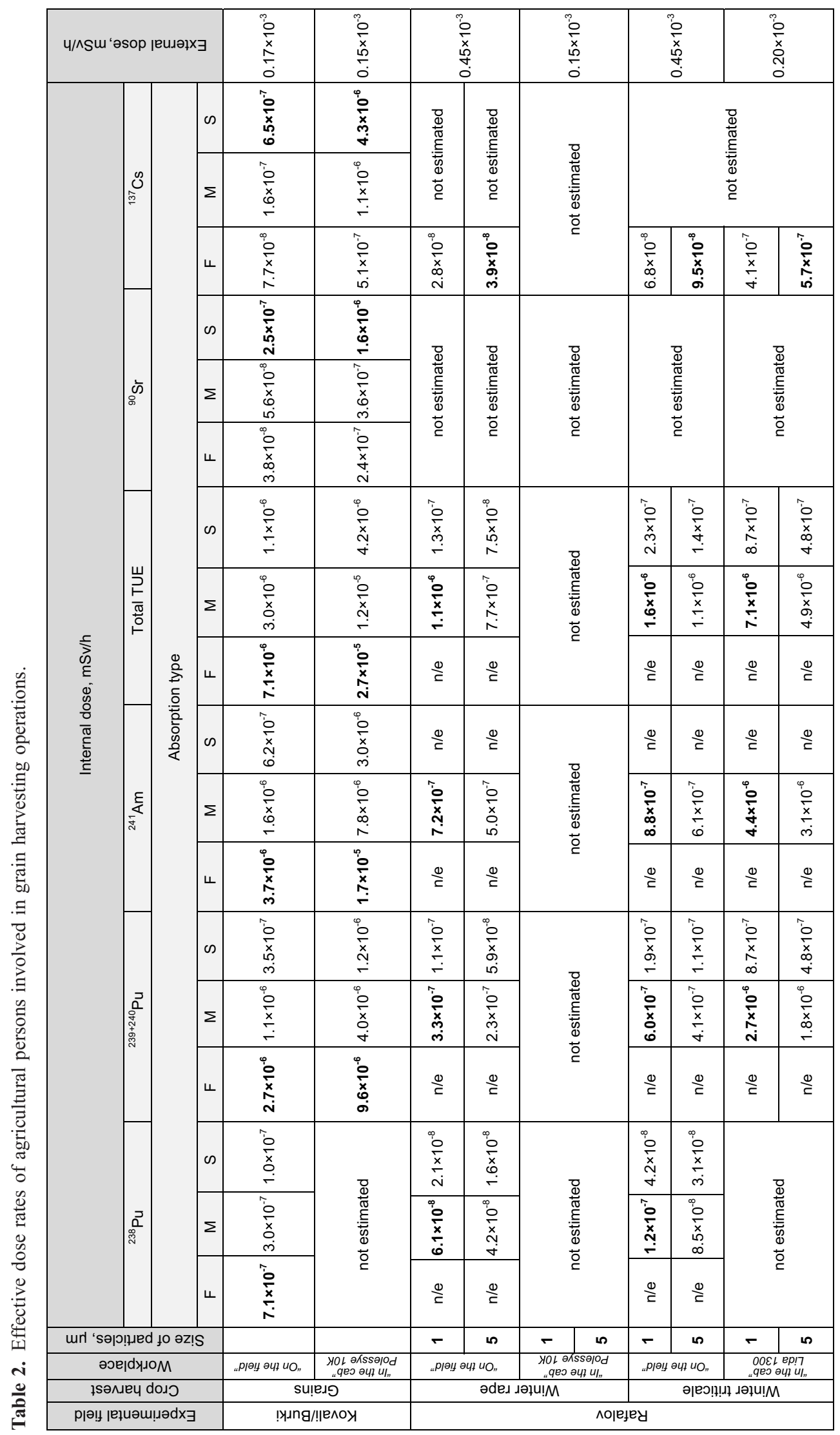




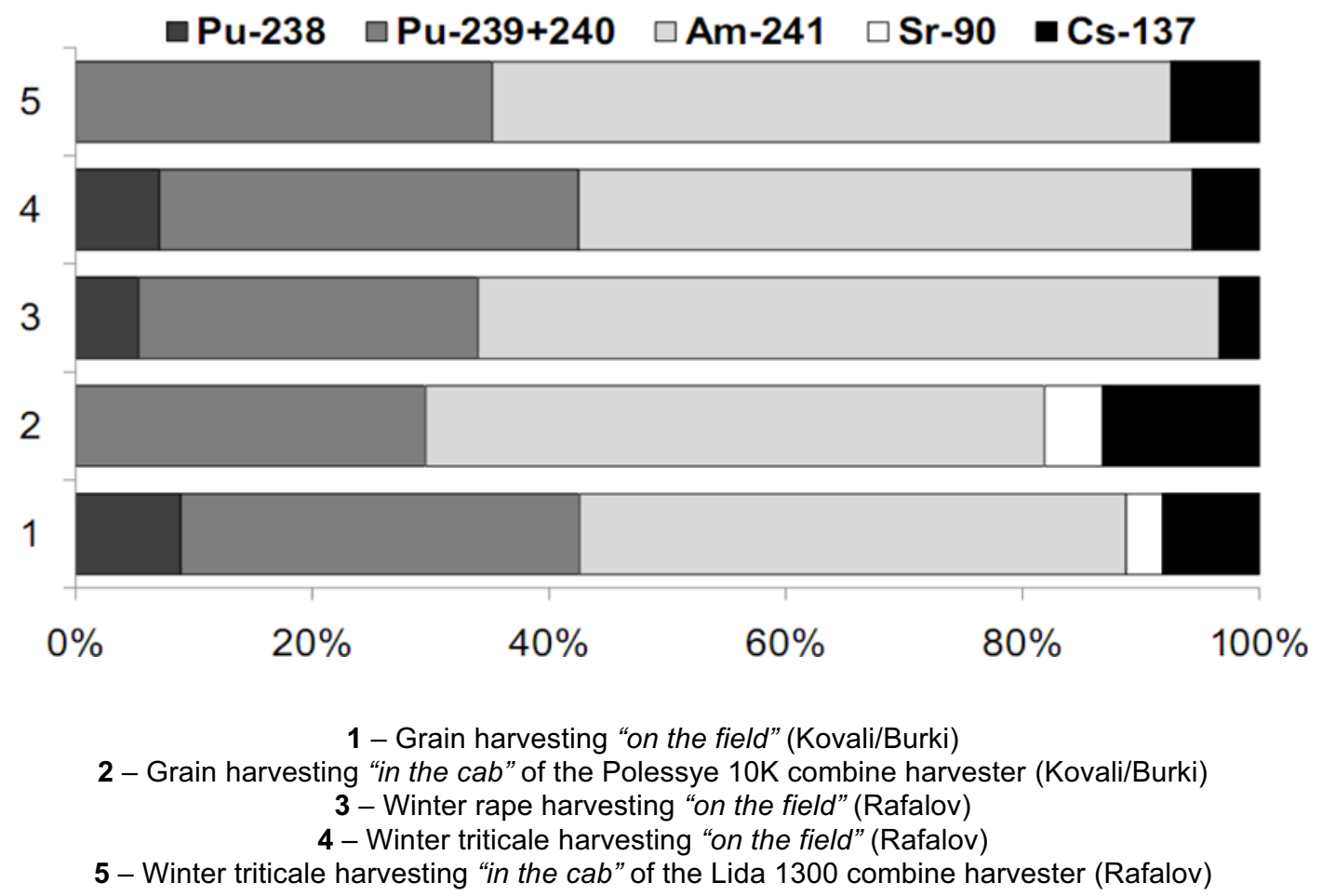

Fig. 2. Inhalation intake of ${ }^{238,239+240} \mathrm{Pu},{ }^{241} \mathrm{Am},{ }^{90} \mathrm{Sr}$ and ${ }^{137} \mathrm{Cs}$ in the structure of the committed effective dose rates.

respectively $6 \%$ and $2-3 \%$ of the regulatory limit for permissible public exposure of $1 \mathrm{mSv}_{\text {year }}{ }^{-1}$.

\section{Conclusion}

This study is focused on assessing the inhalation impact of dusty grain harvesting operations implemented on the backyard of a populated area and on the field in the resettled area of the Chernobyl evacuation zone, both located in Gomel region of Belarus. According to the results, the dust factor is a prevailing contributor in developing internal radiation doses of grain harvest workers (i.e. in a populated area with a lower contamination density the doses may be higher than those received in harvesting operations with smaller dust amounts in the resettled area). Committed effective doses of internal exposure due to inhalation intake of all analyzed radionuclides in all "on the field" harvesting operations are up to one order of magnitude lower when compared to the respective doses of internal exposure received "in the cab", given that an operator's cabin has no air conditioning system. Importantly, the highest committed effective doses of internal exposure due to ${ }^{137} \mathrm{Cs},{ }^{90} \mathrm{Sr}$ and TUE total inhalation exposure $\left(3.3 \times 10^{-5}\right.$ $\mathrm{mSv} \mathrm{h}^{-1}$ ) is up to 5 times lower when compared to the lowest dose of external exposure $\left(0.15 \times 10^{-3} \mathrm{mSvh}^{-1}\right)$. In terms of the structure of the committed effective dose rates, ${ }^{241} \mathrm{Am}$ and $238,239+240 \mathrm{Pu}$ are the dominant contributors to doses constituting $82-97 \%$ of the total inhalation exposure in harvesting operations on both fields.

Given that the working activity during the harvest period on the average lasts $140 \mathrm{~h}$, the total doses of external and internal exposure received by harvest workers on both fields are significantly below $1 \mathrm{mSv}_{\text {year }}^{-1}$, the universally accepted limit for public exposure. The highest committed effective doses of internal exposure due to inhalation intake of ${ }^{241} \mathrm{Am}$, ${ }^{238,239+240} \mathrm{Pu},{ }^{137} \mathrm{Cs}$ and ${ }^{90} \mathrm{Sr}$ are developed in case an operator's cabin is continuously left open, or if it has no air conditioning system. To protect harvest workers from receiving high doses of internal exposure, the present study recommends to employ agricultural machinery with operator cabins safely sealed and equipped with air conditioning systems, as well as to minimize the working time of field workers involved in harvest operations in the open air. To protect harvest workers against external exposure, it is considered highly efficient to implement combined technological operations (e.g. simultaneous application of fertilizers and herbicides) in order to reduce the time spent by workers in the areas of increased radiation background and minimize dust exposure.

Acknowledgement. The authors would like to express their immense gratitude to Aliona A. Mikhailova (RIR) for her tremendous translation, editing and proofreading work and her overall assistance in production of this manuscript.

\section{References}

CRIA. 2012. Criteria for radiation impact assessment: hygienic requirements. Approved by the resolution of the Ministry of Health of the Republic of Belarus of December 28, 2012, No. 213. 2013. $8 / 26850$.

IAEA. 1999. Generic procedures for monitoring in a nuclear or radiological emergency. IAEA-TECDOC-1092. Vienna: International Atomic Energy Agency.

IAEA. 2000. Generic procedures for assessment and response during a radiological emergency. IAEA-TECDOC-1162. Vienna: International Atomic Energy Agency. 
IAEA. 2011. Radiation protection and safety of radiation sources: international basic safety standards: general safety requirements. Interim edition. Vienna: International Atomic Energy Agency.

Konoplya E et al. 2009. Transuranium elements on the Belarus Territory. Radiats Biol Radioekol 49 (4): 495.

Kut'kov V, Pogodin R, Skryabin A. 1996. Exposure of the population of the Gomel region die to inhalation of Chernobyl fuel particles. Radiation Risk J 7: 131
Lebedev I, Myasoedov B, Pavlotskaya F, Frenkel V. 1992. Plutonium contents in the soils of European part of USSR after accident at Chernobyl NPP. Atomic Energy 72 (6): 594.

NRB. 2000. Basic radiation safety standards registration No. 2.6.1.8127-2000. Belarus Republican Centre of Hygiene and Epidemiology. RSR. 2012. Radiation safety requirements: sanitary standards and rules. Approved by the resolution of the Ministry of Health of the Republic of Belarus of December 28, 2012, No. 213. 2013. 8/26850.

Cite this article as: Podolyak A, Tagai S, Nilova E, Averin V. 2017. Assessment of committed doses received by agricultural workers in grain harvesting operations in the areas of radioactive contamination. Radioprotection 52(1): 37-43. 